\title{
Decision Table with Inventory Turnover Ratio to Solve Operational and Strategic Issues
}

\author{
Surjandy $^{1)^{*}}$, Ita Ratnasari ${ }^{2)}$ \\ ${ }^{1)}$ Information Systems Audit Program, Information Systems Department, School of Information System, Bina \\ Nusantara University \\ Jl. K.H. Syahdan No. 9, Jakarta, Indonesia \\ ${ }^{1)}$ surjandy@binus.ac.id \\ ${ }^{2)}$ Information Systems Department, School of Information System, Bina Nusantara University \\ Jl. K.H. Syahdan No.9, Jakarta, Indonesia \\ 2)ita_ratnasari@yahoo.co.id
}

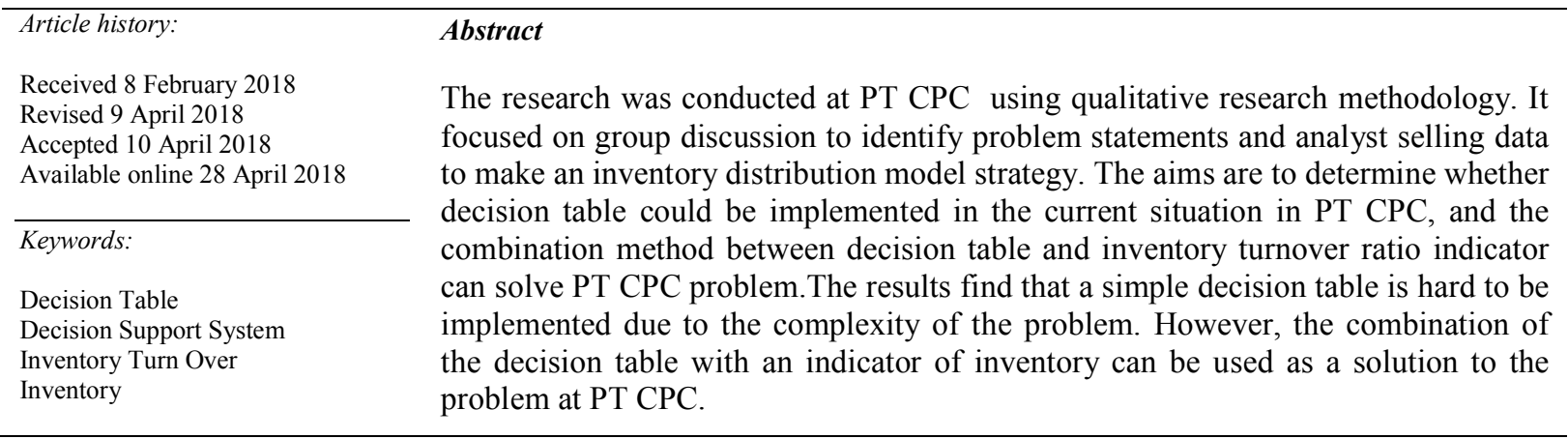

\section{INTRODUCTION}

According to Khan, inventory is an important indicator [1][2]. In every company, it should represent the stocks available of the raw materials, the work-in-process for the items and the finished goods of the company, so it meets customers' orders. Uncertain high demand, various product, and customer service indicator of the pressure level of the managers to increase inventory in the company. Thus, the company needs to know about the inventory condition and inventory turnover ratio.

According to C. Madhusudhana Rao and K. Prahlada Rao, inventory is one of the critical aspects of the company [3]. However, stated that the successful inventory investment could also be measured by inventory turnover ratio [4]. The turnover of inventory is a ratio of the cost of goods sold to the indicator of inventory average level. It measures the number of times when the product is sold or replaced in a period. Usually, the company has a period of the company to evaluate the inventory. It is to know about the status of inventory. This is one of the measures for the company to stabilize the inventory. The metric generally used to measure the performance of the company's operational is Inventory turnover ratio. Since the inventory turnover ratio is also scaled inventory to sales, it might be used to evaluate the progress performance over time by comparing the inventory performance.A high turnover ratio indicates efficient management of inventory. For example, the stock sold faster compare to the amount of average of inventory in stock. Therefore, a low turnover ratio may indicate an inefficient of inventory management.

The inventory turnover ratio became a successful indicator of the selling process in each store [4]. Inventory turnover ratio makes the management easier to make the decision. The inventory turnover ratio combined with decision table makes management easily see the potential area to grow as well. The complex decision is because of the combination of many store location and types of inventory items [5][6][7]. Similarly, agreed that the inventory turnover ratio was one of the measurement indicators to measure the number of times inventory sale in the company

\footnotetext{
${ }^{*}$ Corresponding author
} 
[3]. The inventory turnover ratio was a common measure of the operational efficiency of the company in managing the assets. Minimizing inventory reduces costs. Hence, it improves the profitability performance of the company. Ideally, the inventory turnover ratio should be calculated as units are sold and divided into available units.

PT CPC is a distributor of Kawasaki motorcycle in Cikarang, West Java. It distributes Kawasaki motorcycle to several locations in Indonesia. It receives the inventory of motorcycle directly from the Kawasaki manufacturer. Moreover, the sales regulation from manufacturer keeps changing time to time, with the new regulation of Kawasaki motorcycle; it faces difficulty in following the regulation. Then, the unsold inventory or dead stock in distributor branches also becomes the main problem due to improper inventory distribution. Improper inventory delivery of motorcycle in a distributor branch causes a different amount of inventory with another branch. To move the inventory from one branch to another branch will cost money and time. The other problem is PT CPC can not request certain numbers of motorcycles. The manufacturer will deliver certain numbers of motorcycles based on regulation of manufacturer. This is about the difficult condition in PT CPC to identify the number of inventory and type of motorcycle that should deliver to the stores. However, the management wants to grow the business by opening another store at several locations and strategic decision method to support daily operation due to sales strategy of the manufacturer. For example, a manufacturer of Kawasaki motorcycle will deliver 60 units every month, and the quantity keeps changing.

User group discussion is used to identify the problem of inventory delivery before. Currently, there is no guidance on inventory delivery. It is only by request. The wrong inventory delivery can happen and create an idle of inventory (takes a long time to sell the inventory). Relocation cost due to idle inventory also happens. Thus, it needs the proper strategy to reduce unnecessary cost and improve sales profit for the company to develop.

One of the suggested strategies is a decision table with inventory turnover ratio. It is a combination of decision table and inventory turnover ratio. The combination can make PT CPC make the decision for inventory delivery and also can be used to control sales turnover speed. If management decides to choose aggressive sales than management, it can increase the inventory turnover ratio. The indirect impact to PT CPC is company profit. By using the decision table with inventory turnover ratio management, it can see where is the potential store that needs to be developed in the future.

Next, this research has two aims. First, it is to find out whether decision table could be implemented in the current situation in PT CPC. Second, it is to see whether decision table with inventory turnover ratio indicator can solve the problem. The researchers also use a decision table, the decision table was an easy and simple method that could be implemented in daily activities and informal design. The practice of the decision table has led to many types of extensions and interpretations. According to Yuhua Qian, J Liang, D Li decision table could be used for performance measurement [8]. Meanwhile, according to Karel Dejaeger, Jan Vanthienen and Bart Baesens, and Jose J. Castro-Sanchez, L. Jimenez, Juan Moreno, and Luis Rodriquez, decision table consists of four quadrants area and is separated by vertical and horizontal lines [7][9]. The example can be seen in Table 1.

TABLE 1

DECISION TABLE SAMPLE

\begin{tabular}{ccccc}
\hline \hline Weight & $\begin{array}{c}\text { Boy } \\
<\mathbf{3 0 ~ K g s}\end{array}$ & $\begin{array}{c}\text { Boy } \\
\text { 30Kgs } \geq\end{array}$ & $\begin{array}{c}\text { Girl } \\
<\text { 30Kgs }\end{array}$ & $\begin{array}{c}\text { Girl } \\
\text { 30Kgs } \geq\end{array}$ \\
\hline Reject & $\mathrm{X}$ & & & $\mathrm{X}$ \\
Accept & & $\mathrm{X}$ & $\mathrm{X}$ & \\
\hline
\end{tabular}

The explanation from Table 1, the rules are as follows.

Reject if the boy's weight $<30 \mathrm{kgs}$

Accept if the boy's weight $\geq 30 \mathrm{kgs}$

Accept if the girl's weight $<30 \mathrm{kgs}$

Reject if the girl's weight $\geq 30 \mathrm{kgs}$

Table 1 is the standard decision table sample with a very simple option, it will be used to solve a simple problem such as for the example shown above for boy selection with the weight $30 \mathrm{kgs}$ above, for girl selection with the below 30kgs. However, with this model is not possible to use to solve PT. CPC problem. Therefore, the combination model of the decision table and inventory turnover ratio indicator can solve the PT. CPC problem. 


\section{METHODS}

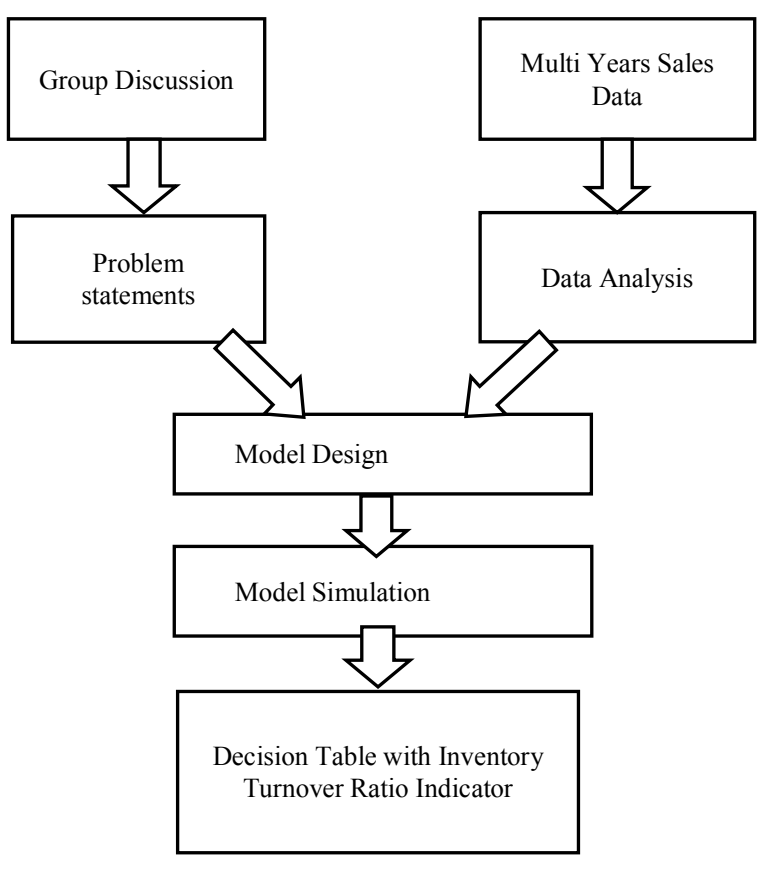

Figure 1 Research Design

O’Brien, Ilene B.Harris, Thomas J.Beckman, Darcy A.Reed, and David A.Cook stated that the research design was very important [10]. The proper design made a good result as said by Elliot et.al [10][11]. Thus, this research uses the qualitative method to identify PT CPC problem, design a suitable model forthe solutions. The research design is in Figure 1.

According to O'Brien, Ilene B.Harris, Thomas J.Beckman, Darcy A.Reed, and David A.Cook, data collection and data analysis are the important processes linking the research question to the conclusion [10]. Twining, Heller, Nussbaum, and Tsai also Allison Tong, P Sainsbury, and J Craig stated similar thing [12][13]. In this research, it uses three-year motorcycle sale records and types of motorcycle sold in each location. By having this sale data, it is easy to make a proper analysis.

There are several steps in the qualitative research, the frist is Focus Group Discussion(FGD) from the FGD comeout with the problem statements, the problem found such as unpredictable motorcycle types receive from the manufacture and unidentify the quantity of stock from each type, no clear management strategy regarding turnover inventory ratio. The management as part of the FGD member is to getthe high level (strategic) problem and future startegic growth of the company, however, the operational and the sales FGD team isto identify the opeartional level problem.

The second, beside the FGD, another part process is analys multiyear sales data, the data used to make a formulation of turnover inventory ratio. The combination between decition table and the formulation turnover inventory ratio, it makes a model to solve the problem, however, the new model need to validate to be sured can be used as a solving problem model. The simulation process as part of the validation model conducted in the store and the result of the simulation as the validation model reviewed by the representative team (the management team and the operational team).At the end of the simulation model validation result show that the model can be used to solve PT. CPC problem.

\section{RESUlts}

The qualitative method is used to find the cause of the problem. The sales report from PT CPC gives clear information about the problem. Data of sales from April 2011 to March 2013 are used. The management of PT CPC also informs the plans to develop sales for the next two years see Figure 2. The management wants to develop the business by opening a new branch at several locations. Figure 2 shows the fluctuation of sales activities. It describes the percentage of a model of the motorcycle which is sold. It is also a comparative history of monthly sales data 
about motorcycle sale from 2011 to 2013.It can be seen that February 2013 has the highest sales. Meanwhile, December 2011 is the lowest sales. The sales fluctuate month to month. This information is important to make the right decision of delivery of motorcycle inventory to the store. The combination of decision table and inventory indicator ratio makes a method which can be used as a distribution strategy. It is by combining decision table to minimize improper inventory delivery to the store. The indirect impact of the distribution strategy is the reduction of unnecessary cost like inventory relocation cost from one store to another store and minimization of the dead inventory item.

Figure 2 shows the sales by month from April 2011 until March 2013.The graphics transaction show very dynamic transaction and the company need inventory strategy to minimize the dead inventory that may raise the operational cost and future enhancement of sales. The problems were happened by seeing the below in Figure 3 for $0 \%$ and 1\% of product sold in Q1 2013 but in fact, the product exists and after an internal investigation by management found that there are several canceled orders because of unavailability product at the store, however, the available stock at other store location.

Thereafter having the required information and combining it in decision table with inventory turnover ratio, it helps management and user to run the business. The operation can perform the business easily after management has decided by using the inventory turnover ratio indicator.

A decision table with inventory turnover ratio is to solve the problemin PT CPC. By using it, PT CPC can make the decisionregarding delivery inventory to the right store, and the quantity of inventory and model of motorcycle delivered to the store and improve the profit. Table 2 shows the decision table with inventory turnover ratio template in Store A, B, and C.

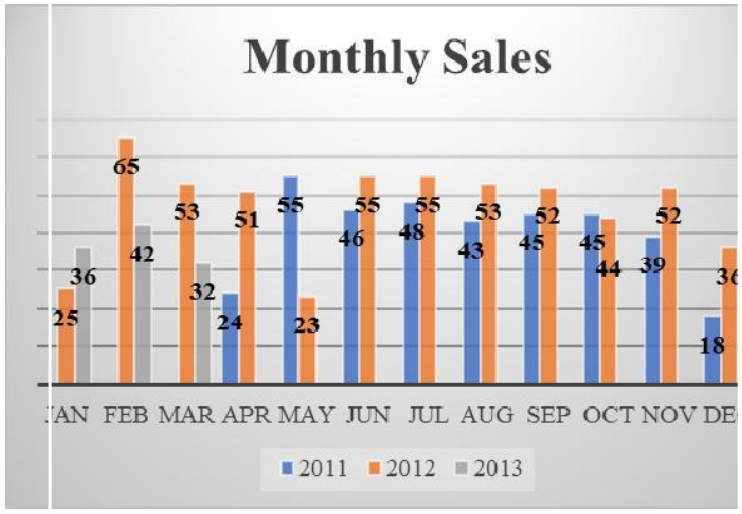

Figure 2 Multi Year Sales Data

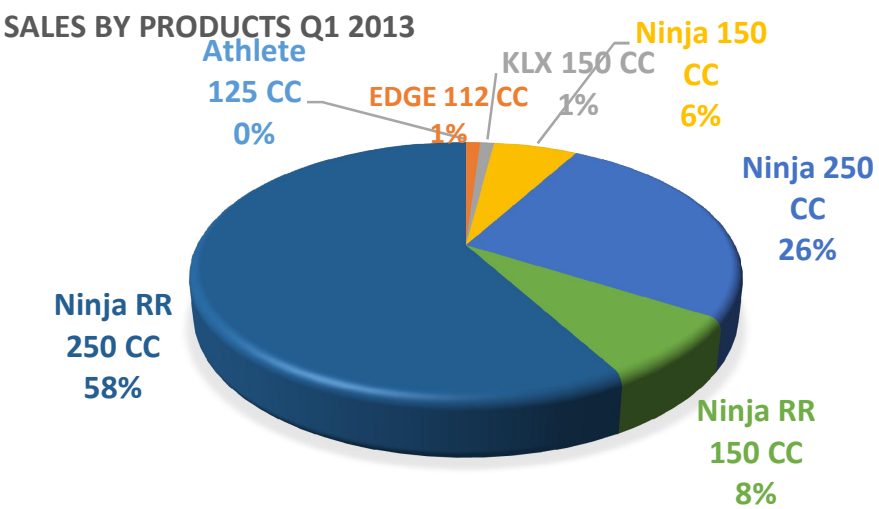

Figure 3 Data of Sales Group by Products 
The description for the template table, the number of goods sold for the item of motorcycle mentioned in Store A is nA. Meanwhile, the goods sold in Store B, C and D are $\mathrm{nB}, \mathrm{NC}$, and D respectively. Moreover, NBA is a number of initial inventory inStore A. For initial inventory, Store B is brand Store $\mathrm{C}$ is nbC. Then nbD is for Store D. Meanwhile, NEA is a number of last in Store A. Thus, neB is a number of last inventory in Store B, is a number of last inventory in Store $\mathrm{C}$ and neD is a number of last inventory in Store D is.

TABLE 2

THE DECISION TABLE WITH INVENTORY TURNOVER RATIO TEMPLATE

\begin{tabular}{|c|c|c|c|c|c|c|}
\hline & \multicolumn{2}{|c|}{ Inventory } & \multicolumn{4}{|c|}{$<$ Inventory Name $>$} \\
\hline & Beginning & Ending & $\mathbf{n A}$ & nB & $\mathbf{n C}$ & nD \\
\hline Store A & $\mathrm{nbA}$ & neA & nAITR & & & \\
\hline Store B & $\mathrm{nbB}$ & neB & & nBITR & & \\
\hline Store C & $\mathrm{nbC}$ & neC & & & nCITR & \\
\hline Store D & $\mathrm{nbD}$ & neD & & & & nDITR \\
\hline$\cdots$ & $\cdots$ & $\cdots$ & $\cdots$ & $\cdots$ & $\cdots$ & $\cdots$ \\
\hline \multicolumn{3}{|c|}{ ITR Indicator } & nITR & nITR & nITR & $\ldots$ \\
\hline \multirow{2}{*}{\multicolumn{3}{|c|}{ Reject }} & nAITR < nITR & nBITR $\geq$ nITR & nCITR $\geq$ & $\ldots$ \\
\hline & & & & & nITR & \\
\hline \multicolumn{3}{|c|}{ Accept \& \% Delivery } & & $\mathrm{n} \%$ & $\mathrm{n} \%$ & $\ldots$ \\
\hline
\end{tabular}

Furthermore, ITR is inventory turnover ratio that is set by management. It can be used by management to speed up the sales revenue. Thus, nitrate is inventory turnover ratio. Then, nAITR is the inventory turnover ratio in Store A. For Store B, it is bitter, Store C is nCITR and Store D is DTR. The calculation of nAITR/nBITR/NCR/nDITR comes from a total number of goods sold divided by average inventory in Store A, B, C, and D. The equations are as follows.

$$
\begin{aligned}
& n A I T R=\frac{n A}{((n e A-n b A) / 2)} \\
& n B I T R=\frac{n B}{((n e B-n b B) / 2)} \\
& n C I T R=\frac{n C}{((n e C-n b C) / 2)} \\
& n D I T R=\frac{n D}{((n e D-n b D) / 2)}
\end{aligned}
$$

Then, theoptions for rejection or acceptance are as follows.

If $n$ AITR $<$ nITR than REJECTED else ACCEPTED

If $\mathrm{nBITR}<\mathrm{nITR}$ than REJECTED else ACCEPTED,

If $n$ CITR $<$ nITR than REJECTED else ACCEPTED.

If $\mathrm{nDITR}<\mathrm{nITR}$ than REJECTED else ACCEPTED.

For the formula can be said that if inventory turnover ratio for the inventory in the certain stories below the inventory turnover ratio from the target of management, the store will not receive for the new inventory. Meanwhile, If inventory ratio equals or is above inventory turnover ratio from the target of management then the store will receive new inventory. The decision table with inventory indicator makes management in PT CPC easy to set up the sales turnover. Moreover, Beatriz Recio et.al, Eduardo Natividade-Jesus et al, and Jose J. Castro-Sanchez et.al said the decision table based on the computer could be used as a solution [14] [15] [7].

This research uses two examples model to simulation implementation in analyzing two models of a motorcycle with decision table with inventory turnover ratio to show the method that may apply to a business that helps management in making decisions. The 2 simulation implementation models represented 2 inventory turnover strategies that may decide in the early business year.

The simulation for the model as an example for Kawasaki Ninja RR. Table 3 shows the decision table with moderate inventory turnover ratio (see score 2 at ITR Indicator in Table 3) for Kawasaki Ninja RR. 
The number of goods sold in Store A is two units of Kawasaki Ninja RR. Meanwhile, the number of goods sold in Store B aretwounitsand Store C is eight units. The number of goods sold in Store D is one Kawasaki Ninja RR. For Store A, the initial inventory of Kawasaki Ninja RR is two and the last inventory is five. Then, it is three and four for the initial and last inventory respectively in Store B. Meanwhile, Store C has a unit as the initial inventory and two units as the last inventory. The initial inventory of Kawasaki Ninja RR is four and the last inventory is three for Store D. Moreover, the inventory turnover ratio of Store A is 1, Store B is 4, and Store C is 16.For Store D, it has no inventory turnover ratio. Next, inventory turnover ratio set by the management two.It can mean that the management chose the unaggressive selling strategy.

TABLE 3

DECISION TABLE SIMULATION WITH INVENTORY TURNOVER RATIO FOR KAWASAKI NINJA RR

\begin{tabular}{lcccccc}
\hline \hline & \multicolumn{2}{c}{ Inventory } & \multicolumn{3}{c}{ Kawasaki Ninja RR } \\
\hline & Initial & Last & $\mathbf{2}$ & $\mathbf{2}$ & $\mathbf{8}$ & $\mathbf{1}$ \\
Store A & 2 & 5 & 1 & & & \\
Store B & 3 & 4 & & 4 & & \\
Store C & 1 & 2 & & & 16 & \\
Store D & 4 & 3 & & & & 2 \\
\hline ITR Indicator & & & 2 & 2 & Reject & \\
\hline Reject & & & Reject & & & $80 \%$ \\
\hline Accept \& \% Delivery & & & & & & \\
\hline
\end{tabular}

The result of the decision table will show to PT CPC as a distributor that it should not deliver Kawasaki Ninja RR to Store A and StoreD. It can be said that performance of Store A and Store D is below the target.

Store B will receive $20 \%$ of the inventory of Kawasaki Ninja RR from PT CPC. For example, if the manufacturer decides to deliver 100 units of Kawasaki Ninja RR to PT CPC, it means Store B will receive 20 units of Kawasaki Ninja RR. Meanwhile, Store C will receive $80 \%$ of the inventory of Kawasaki Ninja RR from PT CPC. If the manufacturer delivers 100 units of Kawasaki Ninja RR to PT CPC, Store C gets 80.

The second implementation simulation example method by choosing Kawasaki EDGE product and use more aggressive turnover indicator by changing the ITR Indicator into 4 (see the ITR Indicator score at Table 4).

TABLE 4

DECISION TABLE SIMULATION WITH INVENTORY TURNOVER RATIO FOR KAWASAKI EDGE

\begin{tabular}{lcccccc}
\hline \hline & \multicolumn{2}{c}{ Inventory } & \multicolumn{5}{c}{ Kawasaki EDGE } \\
\hline & Initial & Last & $\mathbf{1}$ & $\mathbf{1}$ & $\mathbf{1 0}$ & $\mathbf{5}$ \\
\hline Store A & 2 & 5 & 1 & & & \\
Store B & 2 & 4 & & 1 & & \\
Store C & 1 & 2 & & & 20 & \\
Store D & 1 & 2 & & & & 10 \\
\hline ITR Indicator & & & 4 & 4 & 4 & 4 \\
\hline Reject & & & Reject & Reject & & \\
\hline Accept \&\% Delivery & & & & $67 \%$ & $33 \%$ \\
\hline
\end{tabular}

The number of good sold in Store A and Store B is a unit of Kawasaki Ninja RR. Store C sells ten units and Store $\mathrm{D}$ is five units.

The initial inventory of EDGE is two and the last inventory is given Store A. It is two and four for the initial and last inventory respectively in Store B. Then, Store $\mathrm{C}$ has a unit as the initial inventory and two units as the last inventory. For Store D, the initial inventory for Kawasaki EDGE is a unit, and the last inventory is two units. Moreover, the inventory turnover ratio of Store A and Store B is 1 , Store C is 20, and Store C is 16.The inventory turnover ratio Store D is 10. Management has decided more aggressive strategy in selling Kawasaki EDGE than Kawasaki Ninja RR. Therefore, the inventory turnover is four.

\section{DISCUSSION}

The result shows that performance of Store A and Store B in selling Kawasaki EDGE does not achieve the target.The performance of the stores is below management requirement. However, Store $\mathrm{C}$ will receive $67 \%$ of Kawasaki Edge and Store D will get 33\%. The presumption of the manufacturer will deliver the inventory of motorcycle Kawasaki EDGE 100 units to the distributor (PT CPC), 67 units will be delivered to Store C, and 33 units of motorcycle Kawasaki EDGE will be for Store D by PT CPC. 
Therefore, the combination of decision table with inventory turnover ratio is a very useful method to solve issues in PT CPC in delivering an inventory of motorcycle. Besides that, the management can easily decide to deliver the inventory to the right location. It also can help PT CPC to improve the sales target by increasing inventory turnover indicator. The last, management can easily grow the business by looking at the highest turnover ratio indicator for each store or location. Thus, decision table with inventory turnover ratio still needs to be improved for future flexibilities for other complex cases. For example, the cases that require another variable like motorcycle spare part that has different justification in business.

\section{CONCLUSIONS}

PT CPC is one of Kawasaki motorcycle distributors. In Indonesia, it distributes motorcycle for several stores in several cities. As a distributor, it receives the motorcycle inventory directly from the manufacturer. However, the manufacturer always improves the sales strategy without informing the distributor. The inventory of manufacturer and inventory delivery become pressure to PT CPC. Therefore, it has a problem with inventory distribution strategy.

The researchers found that adjusted decision table with inventory turnover indicator become an effective decision tool that makes management control the inventory and improves sales easily. The research also implies that PT CPC needs to improve the operational activities, especially for delivery inventory. It can be done by decision table with inventory turnover indicator. It makes operational can take direct decision for delivery and the number of items to be delivered. Besides that, PT CPC can also speed up the sales process because of proper inventory delivery to the store and reduce unnecessary cost due to improper delivery inventory items.

The implication for education is the adjustment of the decision table. It gives more flexibility of decision table to solve the more complex problem rather than the simple decision table that can only solve the simple. Thus, decision table with inventory turnover ratio can also be used for future business growth by seeing the highest inventory turnover indicator store. The limitation of this research is the solution where the solution is only for the specific purpose, and to generalize the model need to future research. The improvement of the respondent required to see the other problem and another kind of business.

\section{REFERENCES}

[1] J. Vanthienen, and B. Baesens K. Dejaeger, "An empirical evaluation of the comprehensibility of decisiontable, tree,and rule based predictive models," Decision Support System, vol. 51, no. 1, pp. 141-154, 2011.

[2] M.H.A. K.Khan, "An Empirical Analysis of Inventory Turnover Performance Within a Local Chinese Supermarket," European Scientific Journa, vol. 12, no. 34, pp. 145-157, December 2016.

[3] C.M Raoa K. P. Raob, "Inventory Turnover Ratio as a Supply Chain Performance Measure," Serbian Journal of Management, vol. 4, no. 1, pp. 41-50, April 2009.

[4] Marijan Karić, Ivan Kristek, and Maja Vidović, "Measuring the inventory turnover in distributive trade," in Business Logistics in Modern Management, 13th international scientific conference, 2013, pp. 83-93.

[5] L. Bruynseels, B. Baesens, M. Willekens, and J. Vanthienen D. Martens, "Predicting Going Concern Opinion With Data Mining," Decision Support System, vol. 45, pp. 765-777, January 2008.

[6] M. Antrop, P. Bogaert, P. De Maeyer, B. Derudder, T. Neutens, V. Van Acker, and N. Van De Weghe F. Witlox, "Introducing Functional Classification Theory To Land Use Planning by Means of Decision Table," Decision Support System, vol. 46, no. 4, pp. 875-881, 2009.

[7] L. Jimenez, J. Moreno, and L. Rodriguez J. J. Castro-Schez, "Using Fuzzy Repertory Table-Based Technique For Decision Support," Decision Support System, vol. 39, no. 3, pp. 293-307, 2005

[8] Yuhua Qian, Jiye Liang, Deyu Li, Haiyun Zhang, and Chuangyin Dang, "Measures for Evaluating The Decision Performance Of a Decision Table in Rough Set Theory," Information Sciences, vol. 178, pp. 181-202, 2008.

[9] K. Dejaeger, C. Mues, J. Vanthienen, and B. Baesens J. Huymans, "An empirical evaluation of comprehensibility of decisiontable, tree and rule based predictive models," Decision Support System, vol. 51, no. 1, pp. 141-154, 2011.

[10] I. B. Harris, T. J. Beckman, D. A. Reed, and D. A. Cook B. C. O. Brien, "Standards For Reporting Qualitative Research," Academic Medicine, vol. 89, no. 9, pp. 1245-1251, September 2014.

[11] C. T. Fischer, and D. L. Rennie R. Elliott, "Evolving Guidelines For Publication Of Qualitative Research Studies in Psychology and Related Fields," British Journal of Clinical Psychology, vol. 38, pp. 215-229, 1999.

[12] Peter Twining, Rachelle S. Heller, Miguel Nussbaum, and Chin-Chung Tsai, "Some guidance on conducting and reporting qualitative studies," Computers \& Education, vol. 106, pp. 1-9, 2017.

[13] A. Tong, P. Sainsbury, and and J. Craig, "Consolidated criteria for reporting qualitative research ( COREQ ): a 32-item checklist for interviews and focus groups," Int J Qual Health Care., vol. 19, no. 6, pp. 349-357, 2007.

[14] J. Countinho-Rodrigues, and C.H. Antunes E. Natividade-Jesus, "A multicriteria decision support system for housing evaluation," Decision Support System, vol. 43, no. 3, pp. 779-790, 2007.

[15] B.Recio, J.Ibáñez, F.Rubio, and J.A.Criado, "A Decision Support System For Analysing The Impact of Water Restriction Policies," Decision Support Systems, vol. 39, no. 3, pp. 385-402, May 2005. 